\title{
Temporal issues in life cycle assessment-a systematic review
}

\author{
Stefan Lueddeckens ${ }^{1,2} \cdot$ Peter Saling ${ }^{1,3} \cdot$ Edeltraud Guenther ${ }^{1,4}$
}

Received: 1 August 2019 / Accepted: 13 April 2020 / Published online: 4 May 2020

(C) The Author(s) 2020

\begin{abstract}
Purpose Case studies on life cycle assessments frequently admit that the precision of their outcome could be undermined due to temporal issues, though they usually refrain from offering much more detail. In addition, available overview papers and reviews on problems and challenges in LCA do not address the whole range of temporal issues. As those are major sources of inaccuracies and influence each other, it is important to get a clear picture of them, to close gaps in definitions, to systemize temporal issues, and to show their interdependencies and proposed solutions. In order to identify the state of science on those questions, we conducted a systematic literature review.

Methods We first systematized temporal issues based on ISO $14040 \mathrm{ff}$ and divided them into six types: time horizon, discounting, temporal resolution of the inventory, time-dependent characterization, dynamic weighting, and time-dependent normalization. Building on that, we identified suitable search terms and developed an analysis grid for the content analysis. We included only methodological papers and case studies with original findings on solutions for temporal issues. Bibliographic data, impact types, industrial fields, and methodological contributions were analyzed.

Results and discussion Literature differentiates between different types of time horizons. There is one for the whole assessment, defined in goal and scope, one for the life cycle inventory, and one for the impact characterization. Setting a time horizon for the assessment is regarded as equivalent to the application of discounting. Both very long and very short time horizons of the assessment are not practical depending on the topic assessed in the LCA. Very short ones would offend the principle of intergenerational equality, while very long ones would marginalize short-term actions and thereby reduce incentives to act. There is consensus in the literature that temporally differentiated life cycle inventories and time-dependent, or at least time horizon dependent, characterization improve the accuracy of LCA. Generally, dynamic life cycle assessments are attractive for companies because the calculation results are not only more accurate but are often also lower than in static life cycle assessments. Conclusion The main questions where we did not find consensus are the issue of the length of the time horizon of the assessment and the issue of discounting. Those are regarded as subjective and are encountered with sensitivity or scenario analysis. Further investigations should be taken for a better understanding of this issue and for concrete solutions because their influence on the results of life cycle assessments is often fundamental.
\end{abstract}

\section{Responsible editor: Chris Yuan}

Electronic supplementary material The online version of this article (https://doi.org/10.1007/s11367-020-01757-1 ) contains supplementary material, which is available to authorized users.

Stefan Lueddeckens

ema@mailbox.tu-dresden.de

1 PRISMA-Centre for Sustainability Assessment and Policy, 01062 Dresden, Germany

2 Chair of Business Management, esp. Sustainabili ty Management and Environmental Accounting, 01062 Dresden, Germany

3 BASF SE, Corporate Sustainability, Carl-Bosch-Strasse 38, Ludwigshafen am Rhein, 67056 Dresden, Germany

4 Institute for Integrated Management of Material Fluxes and of Resources (UNU-FLORES), United Nations University, Ammonstrasse74, 01067 Dresden, Germany
Keywords Temporal issues - Life cycle assessment - LCA · LCIA · Time horizon · Discounting · Dynamic

\section{Introduction}

\subsection{The temporal dimension in LCA}

Governments and companies are increasingly concerned with a more sustainable use of their resources. Sustainable development (WCED World Commission on Environment and Development 1987) has become a key goal of the global community. Following the well-known phrase "What gets measured, gets managed" (Drucker 1954), decisions on allocations of resources should be founded on data, resulting in a need for sustainability measurement methods. The common 
measurement tool in the field of environmental sustainability is life cycle assessment (LCA), which aims to support decision makers by providing a rational basis for their decisions. This aid can be misleading if the measurement is too inaccurate, making non-effective decisions seem more advantageous than they actually are.

Recently, claims that the bioenergy sector presents a more environmental sustainable alternative have highlighted the fact that disregard or imprecise measurement could result in misdirected investments or even deeper environmental damages. For example, Peters et al. (2011) presented cases where the inclusion of the temporal dimension resulted in biofuels being a less favorable alternative than gasoline. In this context, it was stated that, at the time, the inclusion of temporal issues had been an uncommon practice in LCA. This is also emphasized by McManus and Taylor (2015) who state that temporal issues in biomass-LCA are only handled on an ad hoc basis, mostly as scenario analysis. They regard the biofuel and bioenergy sector as a key driver for methodical developments of LCA, because many issues in LCA, especially temporal issues and consequences, appear there.

LCA was developed as a holistic tool for the assessment of environmental sustainability, with several impact categories and, for the comparison of alternatives, linked to a functional unit (Charlton and Howell 1992). Since 1997, LCA has been standardized in ISO 14040 and 14044. They are general standards, not covering specific aspects in detail. They describe the main steps of LCA as goal and scope definition, inventory generation, characterization, normalization, weighting, and interpretation (ISO 14040:2006-11). As the Brundtland definition on sustainable development- "Development that meets the needs of the present without compromising the ability of future generations to meet their own needs"-already implies, the temporal dimension is a key aspect of sustainability (Held 2016) and needs to be considered in assessments. Held (2016) states that using the concept of time in a conventional, mechanistic way where time is linear, homogeneous, and sometimes reversible, significant potential in understanding the temporal dimension and sustainability as a whole is lost. $\mathrm{He}$ recommends the "timescape" concept invented by Adam (1998) to respect the diversity and multidimensionality of time, e.g., path dependencies, timing, synchronization, and latencies of effects and actions. However, this is complicated to apply in a practical assessment tool. The environmental dimension of sustainability that is assessed by LCA is, in contrast to the social and financial dimension, a purely temporal concept. The ecosystem should remain intact over time, which can be measured by natural scientific figures. However, the social dimension has more concerns in the fields of justice or ethics, in addition to temporal aspects (Colocousis et al. 2017).

There is continued debate over how to integrate the temporal dimension in LCA. ISO 14040 itself states a lack of temporal information in the inventory: "The lack of spatial and temporal dimensions in the LCI results introduces uncertainty in the LCIA results. The uncertainty varies with the spatial and temporal characteristics of each impact category." ISO 14044 states uncertainties in the characterization and weighting phase: "Depending on the environmental mechanism and the goal and scope, spatial and temporal differentiation of the characterization model ... should be considered" and "Weighting steps are based on value-choices and are not scientifically based." Overview literature and reviews show that temporal issues have been a constant problem since the introduction of LCA theory and practice (Owens 1997a; Finnveden 2000; Finnveden et al. 2009; Guinée et al. 2011; Hellweg and Milà i Canals 2014). According to them, many published LCAs and LCA case studies admit temporal issues as a limitation of their outcomes. Nevertheless, temporal issues are rarely described in detail. We did not find any complete definition or systematization of this open field in LCA, but a complete approach is necessary due to the interactions of different temporal issues. Also, up to now, the literature has not produced an overview of temporal issues and their solutions. As the strength of LCA is its standardization and therefore the comparability of different LCAs, it is necessary to close gaps by enhancing the standard and common practice. We approached this research gap by conducting a systematic literature review on the available methodological literature on LCA. To our knowledge, no review on temporal issues in LCA is currently available.

\subsection{Importance of temporal issues}

The lack of recognition of temporal effects in LCA has been known since its introduction in 1997 and published in several papers on limitations of LCA. Owens (1997a) criticizes that temporal differentiation is lost within the common method of aggregating inventory data. This constraint leads to inaccuracies of the impact assessment, which itself can be a function of time. Owens also gives an example on human health impacts where information on emission timings (concentrations) and exposure times are relevant (Owens 1997b). Finnveden (2000) states that the choice of the time horizon of LCA can have a decisive influence on the assessment outcome, especially when assessing long-term heavy metal emissions of municipal waste sites. In his opinion, the choice of the time horizon is mainly an ethical question about rights of future generations. Another field with relevant long-term emissions is nuclear energy. Dones et al. (2005) chose in their LCA study a time horizon corresponding to the half-life of the Thorium230 isotope without discussing the reason for only assessing half of the overall radioactive emissions. Despite early critiques on LCA, Guinée et al. (2011) characterizes the period preceding 2010 as a "decade of elaboration" and states that, subsequently, a period of divergence in methods began. Issues 
not defined precisely enough in ISO 14040 have to be resolved, among them the temporal system boundary and temporal dynamics, depending on goal and scope. Hellweg and Milà i Canals (2014) also raise the question of adequate temporal boundaries and temporal resolution, but also point out that "Enabling a widespread application (of LCA) with 'stable' methods, without paralyzing the relevant methodological developments, remains a challenging task" because "mainstream application of LCA requires simplifications and standardization to enable consistent and easy use in practice". We agree that this is currently the frame for methodological developments.

\subsection{Systematization of temporal issues}

As a systematic literature review based on search terms like "LCA and time" is not suitable because of the many appearances of time in many contexts, it is necessary to narrow the field by systematizing temporal issues through an exploratory literature search and applying logical considerations of the LCA concept. Several highly accepted publications for practitioners have described, in detail, how to perform an LCA and the workflow demanded by ISO 14040. We used the ILCD Handbook (International Reference Life Cycle Data System (ILCD) 2010) and Klöpffer's compendium (Klöpffer and Grahl 2014) to identify direct and indirect temporal issues in LCA. We define direct issues as those, which are logically directly linked to the time dimension, while indirect issues depend mainly on non-temporal effects or decisions, which themselves have secondary temporal issues. ${ }^{1}$ Figure 1 illustrates the main steps in LCA and its corresponding temporal issues.

Indirect temporal issues surface in the discussion of whether to use attributional or consequential approaches (e.g., Brander 2017), where consequences could happen directly or in future periods. The time horizon here is not directly linked with the assessment approach. The consequential approach discussed the enhancement of the physical system barrier from the assessed product or process to a wider technical environment, but that is not primarily a discussion about enhancing the time dimension. The inclusion or exclusion of life cycle stages, like the discussion of cradle-to-gate, cradle-tograve, cradle-to-cradle, is more a matter of responsibility for these stages than a matter of time, although life cycle stages happen on different intervals of the time scale. The end-of-life question, e.g., the question of how to assess recycled products, has the temporal nomenclature, but is rather a logical problem of allocation than a temporal issue. The question of the

\footnotetext{
${ }^{1}$ We discussed "minor" and "major" or "primary" and "secondary" but we think that "direct" and "indirect" fit best to our idea that in direct temporal issues time variables are the key variables, while in minor temporal issues there are other key variables.
}

preference of midpoint or endpoint indicators also has a temporal nomenclature, but is rather a problem of the damage model, where endpoint damage does not necessarily happen later than midpoint damage. The assessment of uncertainty or variability is a statistical problem, of which the temporal dimension is only one of several influences. Huijbregts (1998) defines variability as "stemming from inherent variations in the real world", while uncertainty happens when transforming the real world into LCA models, e.g., because of inaccurate measurements, lack of data, or model assumptions. Uncertainty and variability, as well as technical issues in the modeling of the inventory, are not further discussed in this paper because they are very case specific. The inclusion of temporal issues does no improvement to the sources of uncertainty or variability but includes factors that were disregarded or simplified before. Known data for dynamics that were disregarded before are included. The choice of the time horizon of an assessment or a discount function should not be uncertain but defined by the LCA practitioner. Uncertainties in temporal variables, like the duration of long-term emissions, remain and can be addressed by statistical approaches like Monte Carlo-Analysis.

Direct temporal issues manifest themselves by influencing the amount of temporal data in the LCA for the sake of enhancing/narrowing or particularizing/coarsening the temporal dimension. The enhancing or narrowing affect the issue of an adequate time horizon and normative questions on the weight of environmental impacts within this time horizon (discounting). The particularizing/coarsening affects more technical issues, such as the inventory's temporal resolution and the consideration of temporal dependencies in characterization and normalization. In the following, we refer only to direct temporal issues when we write "temporal issues." There have been attempts to illustrate the temporal dimension of sustainability in general, such as the visualization by Lozano (2008). However, we did not find a helpful illustration for deriving measures to solve temporal issues in LCA. For this purpose, we categorized possible temporal issues in LCA and conducted a subsequent systematic literature review to further classify and subdivide them and to identify and evaluate proposed solutions.

\section{Methods}

Littell et al. (2008) defined the aim of a systematic review as "to comprehensively locate and synthesize research that bears on a particular question, using organized, transparent, and replicable procedures at each step in the process." Zumsteg et al. (2012) introduced this method for aggregative LCA studies. While it is suggested to use systematic literature reviews in combination with content analysis methods in order to extract relationships and opinions or in combination with 
Fig. 1 Systematic overview of temporal issues in LCA. Direct issues are fatly framed

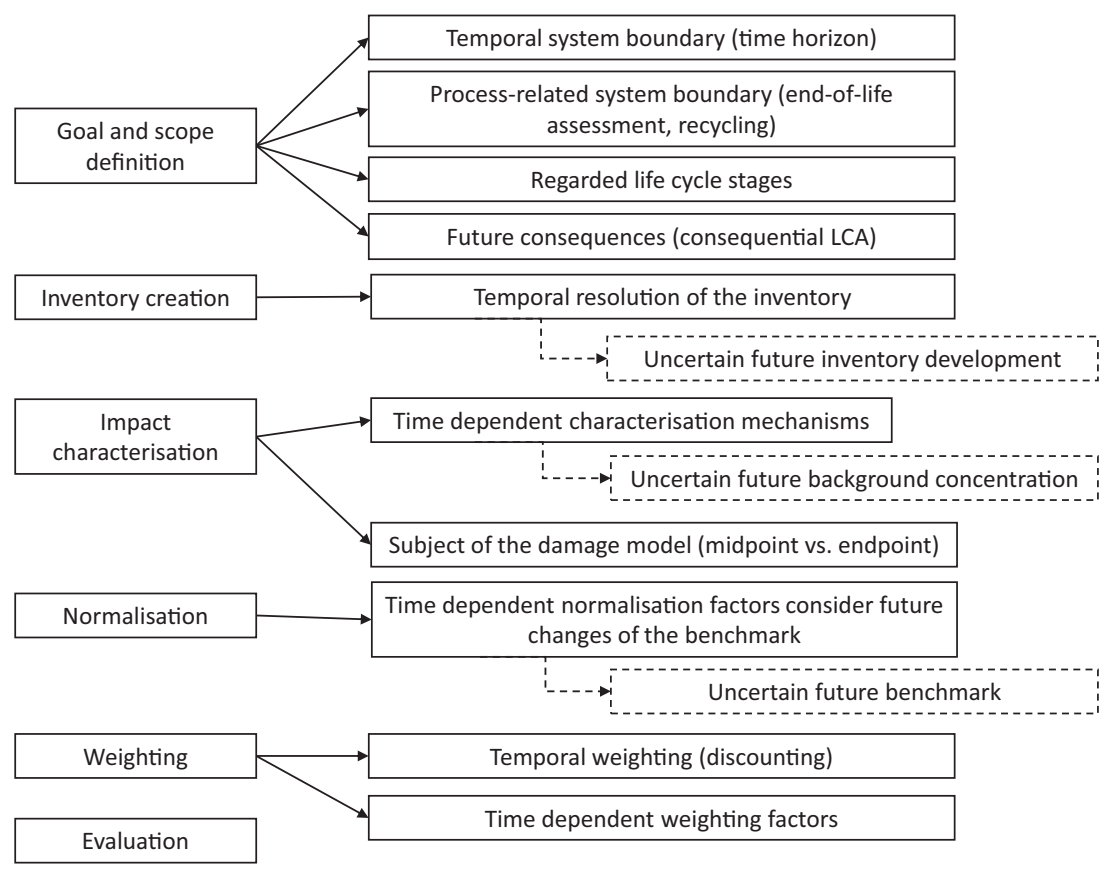

meta-analysis to extract data (Tranfield et al. 2003), we decided to utilize this method to identify as many aspects of temporal issues as possible in a comprehensible way. Our review provides an interdisciplinary and an international overview of the current perception and handling of temporal issues in LCA. It is based on the four steps of a systematic review proposed by Fink (2014) in combination with the structure proposed by Tranfield et al. (2003). In the first step, we selected our research questions, appropriate bibliographic databases, and search terms we found to be suitable according to our pre-systematic review. Our search results were selected by practical review criteria and synthesized subsequently.

Step 1: Our research questions are "How are our six direct temporal issues described in literature?" and "What solutions for temporal issues in LCA are provided by current research literature?" Based on these questions, search terms cannot be directly extracted because kinds of temporal issues must be known to search for the appropriate words in order to find proposed solutions. Besides our knowledge at the beginning of the process and by using a logical derivation of temporal issues, we conducted a presystematic literature review based on Google Scholar search results on terms containing temporal aspects in the life cycle assessment. Our final search term for the database search was (lca OR lcia OR ("life cycle" AND assess*)) AND (time OR timing OR discount* OR dynami* OR tempor* OR "time dependent" OR "time dependency" OR "time distributed" OR "time horizon" OR "time scale" OR "time related" OR "time adjusted" OR "time resolved" OR “intergenerational” OR "inter-generational"). We searched in both titles and abstracts, but because of many false results, the term "time" was limited only to titles and phrases containing "time" like "time horizon" to abstracts. We searched in the major bibliographic databases WebOfScience Core Collection, Academic Search Complete, Scopus, and TEMA (Technik und Management), which are widely accepted databases in the field of environmental sciences. In TEMA it is not possible to search for different terms in title and abstract simultaneously, so we searched for "time" also in abstracts but limited the results in this database to available descriptors "life cycle assessment" and "life cycle evaluation". The search was last updated on December 18, 2018.

Step 2: We included reviewed journal papers in English only to ensure a high international quality standard of our findings. Only papers discussing concrete solutions for temporal issues were accepted. This includes conceptual or theoretical publications as well as empirical ones, with the latter mainly consisting of case studies on LCA methods and rarely specific LCAs, which then must contain a methodological discussion. Empirical papers with pure application of known methods but without deeper methodological discussion as well as theoretical papers only discussing temporal issues without giving appropriate solutions were excluded. The papers must have a remarkable contribution to the topic based on its own 
original research results and should not only cite others in methodological questions. Papers dealing with general scientific questions of inventory modeling were excluded, too. Next, we focused on LCA. There are similarities to other environmental sustainability assessment methods, such as cost-benefit analysis, but substantial differences from others like input-output analysis, where other temporal measures play a role. This includes, for example, occupancy time between inputs and outputs (Omura 2004). A comprehensive overview of sustainability assessment methods can be found in Angelakoglou and Gaidajis (2015). Also, life cycle costing is not a topic of this review. Papers were selected in stages: at first by title, then by abstract, and lastly by the full text. After our search, we added the relevant cited literature to our findings (so-called "snowball search").

Step 3: Positively identified papers are analyzed by utilizing a review protocol. Our analysis contains bibliographic data, a classification of publication type, impact category, industrial sector, and a summary of contributions to the temporal issues. Therefore, we used the following coding in our qualitative data analysis program MAXQDA:

Type of publication

- Methodological/conceptual

- Case study/LCA with methodological discussion

Impact codings

- Climate

- Toxicity or heavy metals

- Land use change

- Other environmental indicators

- General discussion, no specific indicators

Technical sector codings

- Waste/landfills

- Carbon storage

- Transport/mobility

- Buildings

- Production of goods

- Energy

- Biomass production and recycling

Analyzed literature can only have one type of publication, but can handle different impact categories and a mixture of technical sectors. For example, biofuel assessments can have the technical sectors biomass and mobility.

Contributions to temporal issues were coded according to our six direct issues:

- Time horizon

- Temporal weighting/discounting

- Temporal resolution of the inventory

- Time-dependent characterization

- Dynamic weighting

- Time-dependent normalization

Step 4: of the systematic review "Synthesizing our findings" according to Fink (2014) is discussed in the next chapter.

\section{Results}

\subsection{Search results}

The database search yielded 10,179 hits. Sorting out duplicates and non-English papers, the hits were reduced to 5821 . The remaining papers were screened in three steps utilizing our inclusion and exclusion criteria. First, 5174 papers with clearly non-relevant titles were removed. Then the remaining 647 abstracts were analyzed and 368 papers were removed. From the remaining 279 papers, 236 were removed after a full text screening, with the remaining 43 being used in the review (Fig. 2). During the analysis of these papers, we identified

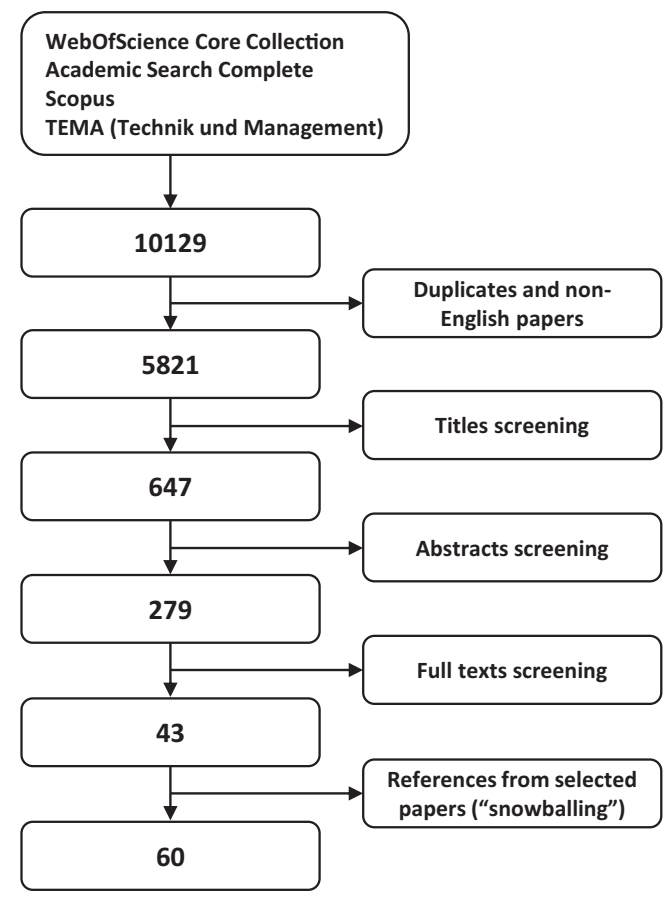

Fig. 2 Literature selection process 
Fig. 3 Time series of reviewed publications

\section{Years and Types of Publications}

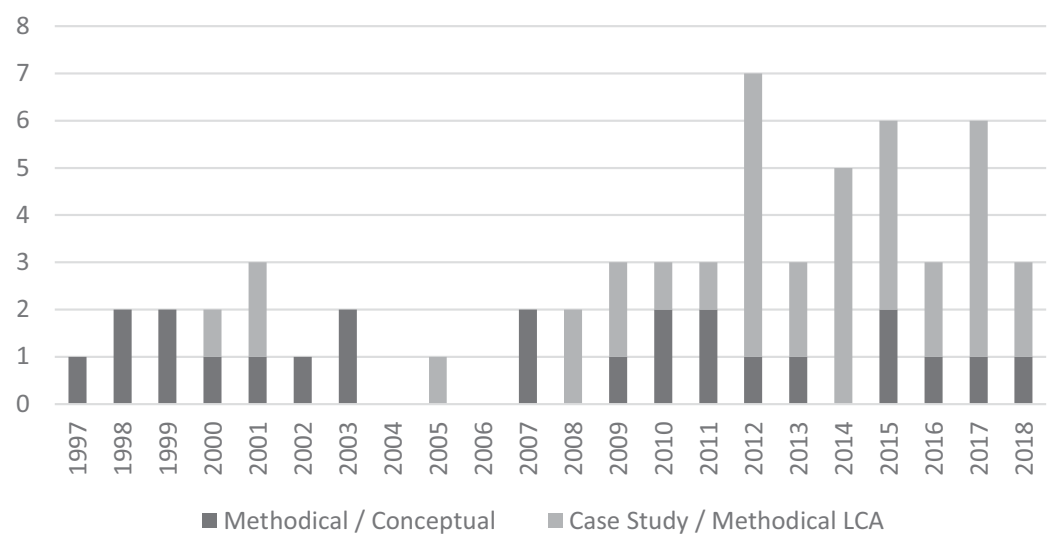

17 references in them as relevant for the review and added them ("snowball search").The total number of reviewed publications was finalized at 60 . The complete review protocol can be found in the electronic supplementary material.

\subsection{Bibliographic analysis}

The oldest publication analyzed is from 1997, the most recent one from 2018. Figure 3 shows a time series of the publications and their types. We analyzed 24 methodological and conceptual papers and 36 case studies and methodological LCAs.

While purely methodological literature remains on a low level over the years, there is a clear trend of research on methodological issues with practical examples. This could be explained by an enhanced availability of data and commercial

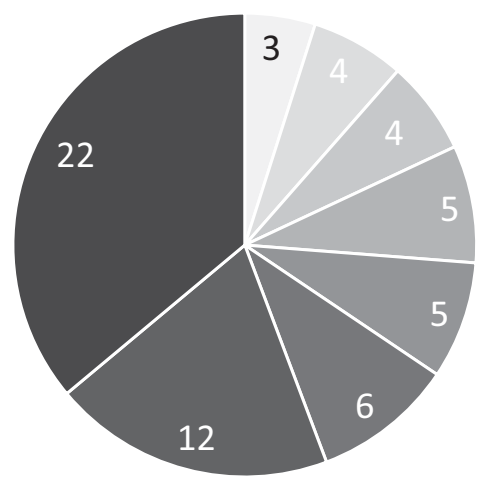

\footnotetext{
Climatic Change

Mitigation and Adaptation Strategies for Global Change

- Science of the Total Environment

Journal of Cleaner Production

- Journal of Industrial Ecology

- Environmental Science \& Technology

- International Journal of Life Cycle Assessment

n others
}

Fig. 4 Distribution of journals of the reviewed literature
LCA databases like Ecoinvent. The rising interest in temporal issues could be influenced by a key publication "Considering Time in LCA" (Levasseur et al. 2010), which was cited by $29 / 36$ of the reviewed papers since 2010, the article itself excluded.

Figure 4 shows the journals where the reviewed literature was published. The International Journal of $L C A$ proved to be the most important journal for the discussion of methods for temporal issues in LCA.

Impacts on the climate are discussed in the majority of reviewed papers (Fig. 5). We assume that the reasons behind this are the high public interest in this topic as well as the availability of data and metrics in the fifth IPCC report. There is also financial interest because of emission trading or subsidies for alternative fuels, which depend on $\mathrm{CO}_{2}$ balances. Furthermore, climate change and pollutions by heavy metals and other toxics are good examples for temporal issues as they have long lasting impacts and time dependencies in their characterization, as $\mathrm{CO}_{2}$ is slowly removed from the atmosphere by natural mechanisms and heavy metals spread and dilute in the ground. As alternative fuels for cars and power plants are usually of biogenic origin, the biomass sector stands out as the most interesting for our selected literature.

\subsection{Solutions for temporal issues}

\subsubsection{Time horizon}

We found that the discussion around time horizons (THs) can be classified into the following topics:

\section{Differentiation of THs}

Literature discusses different types of THs, although it is often not clearly indicated out which type is meant. Saez de Bikuña et al. (2018) differentiate three THs: the TH of the 
Fig. 5 Impact codings and technical codings in reviewed literature

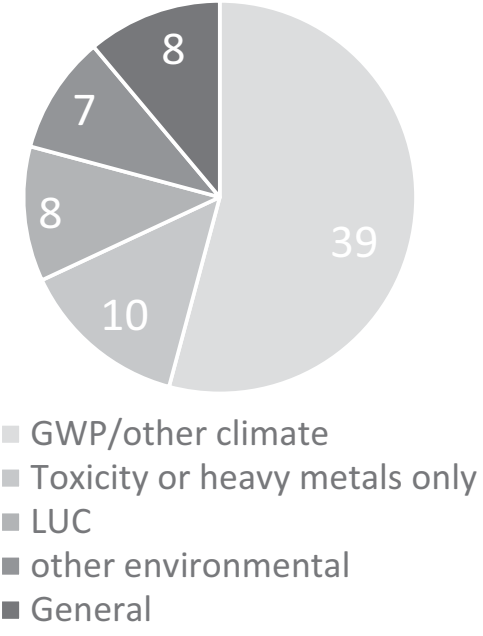

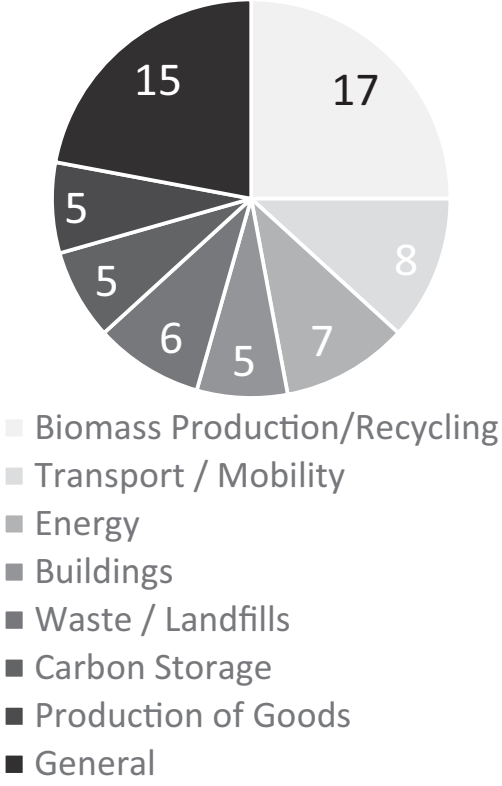

product or service (the length of the life cycle), the TH of the inventory modeling (which can be longer than the life cycle if emissions persist), and the $\mathrm{TH}$ of the impact modeling for characterization. According to Peters et al. (2011), there can be separate THs for each impact category if they have different time scales. There is a question as to whether THs must be consistent. Yu et al. (2018) differentiate between the TH of the assessment, defined in goal and scope, and the TH of the impact assessment. In their case study, they compare different THs for the assessment of road pavements and apply different THs for the time-adjusted Global Warming Potential (GWP, discussed in the characterization section). Almeida et al. (2015) and Levasseur et al. (2010) criticize inconsistencies if the stated TH of the assessment, defined in the goal and scope phase as temporal system barrier, does not fit to the $\mathrm{TH}$ of the characterization. For example, there would be inconsistency if the stated TH of an analysis is 100 years and the GWP100 is applied on a dynamic inventory. In a static LCA, all emissions would be summed up and handled as if they were emitted at the beginning of the lifetime considered. With a dynamic inventory, GWP applied to the emissions of year 99 would lead to an implicit $\mathrm{TH}$ of the assessment of 199 years. For Levasseur et al. (2010), this is a reason to use dynamic characterization. Others do not regard different THs as inconsistent and accept them in LCA (Brandão et al. 2013; Brandão and Levasseur 2011; Menten et al. 2015). BeloinSaint-Pierre et al. (2016) apply the static GWP on a dynamic inventory in a way that emissions in the first year no longer count in the one hundred and first year, but the last emission is counted until the 199th year. Brandão and Levasseur (2011) suggest fixed THs rather than fixed endpoints (certain years) unless the latter is attractive because policy often has fixed temporal goals. Assessments with fixed endpoints cannot be compared well with later LCAs on the same object. They would have a shorter timeframe, so the impact would be reduced or the previous LCAs would need to be recalculated with a new starting point. In most studies, different THs are not discussed and statements on THs concern the TH of the assessment.

\section{Importance of the $\mathrm{TH}$ for the LCA outcome}

Case studies (Huijbregts et al. 2001) as well as methodological literature (Kendall 2012) show the high dependency of LCA results on the chosen TH. The dependency is stronger for short-time emissions, like those of methane in the GWP calculation (Levasseur et al. 2010) and land use change (Schwietzke et al. 2011), where initial emissions marginalize over time. For example, $\mathrm{CH}_{4}$ emissions have a 72 times higher GWP than $\mathrm{CO}_{2}$ in a 20-year TH, but only a 25 times higher GWP in a 100-year TH. Initial land use change in biofuel production raise the cumulative radiative forcing by $5 \%$ over a 50 -year TH but only $2 \%$ over a 100 -year TH. According to Schwietzke et al. (2011), this may be decisive for corn ethanol, which is not much more beneficial than fossil fuel.

\section{Length of $\mathrm{TH}$ as a subjective decision}

Generally, the length of THs is described as a subjective decision (Beloin-Saint-Pierre et al. 2016; Dyckhoff and Kasah 2014; Laratte et al. 2014) or even arbitrary (Brandão and Levasseur 2011). De Rosa et al. (2017) state that a TH depends on the goal and scope of the study. According to Berntsen et al. (2010), a TH should fit to political goals and Levasseur et al. (2012) call it a political decision. Cherubini et al. (2011) state that "tipping point issues and commitment 
periods and targets provide motivation for time-constrained assessment approaches". Even if this is true, Guo and Murphy (2012) propose showing results with other THs than those of political goals for more meaningful results. Several subjective reasons speak for short THs. Bakas et al. (2015) state that long-term effects are often ignored because of complexity, diversity of approaches, and uncertainty together with short time preference of policymakers. According to Lebailly et al. (2014), uncertainty about future mitigation technologies makes a short TH preferable. According to Fearnside (2002), a long TH would marginalize short-term impacts, which would be counterintuitive. Brandão and Levasseur (2011) say that the TH could be representative for the urgency of the environmental problem, with urgent problems having short THs. Brandão et al. (2013) confirm this but admit that short THs would violate the principle of intergenerational equality. Herzog et al. (2003) even say that what a society calls "permanent" is a political decision. Due to the subjectivity of THs, scenario analysis (Guo and Murphy 2012; Kendall and Price 2012; Udo de Haes et al. 1999) or sensitivity analysis (BeloinSaint-Pierre et al. 2016) should be performed, so that the readers of an LCA study can decide on their own. For scenario analysis, $\mathrm{Hu}$ (2018) suggests calculating the different THs for an assessment based on cultural theory. According to this theory, people's attitudes to THs can be divided into four different categories. In cultural theory, summarized by Hofstetter et al. (2000), societies can have the archetypes fatalist (with the shortest $\mathrm{TH}$ ), individualist, hierarchist, and egalitarian (with the longest TH). Implications of cultural theory with suggestions for TH and discounting are discussed in Hauschild et al. (2018). As an alternative to scenario analysis, Dyckhoff and Kasah (2014) handle the TH as a dependent variable on a plot so that decision makers can decide and see intersections or break-even points at certain time points. Fearnside (2001) states that the often applied TH of 100 years is adequate if one thinks of a 50-year-old decision maker who has a personal TH until the death of his grandchildren as the last family members he will personally know. Therefore, there is an opinion in literature, that $\mathrm{TH}$ is a policy decision and should be rather short so that it reflects political goals and that long THs could be abused as an excuse for not acting today. This leads to the question if THs should generally orientate on the current possibilities of acting against environmental impacts instead of measuring impact for current and future generations whereas we have no influence on the action of the latter. There may be a difference in thinking whether the LCA practitioner feels personally involved and wants to act in a foreseeable $\mathrm{TH}$ or whether he wants to measure impact with an intergenerational perspective as an outside observer.

4. Derivation of THs by action orientation and possibilities for gaming
Although it is generally accepted that future generations should not be penalized, there are considerations that long THs marginalize effects of short-term actions, like carbon capture and storage (Almeida et al. 2015; Herzog et al. 2003). Especially an infinite TH would make every sequestration, if assessed with the GWP indicator, useless (Brandão et al. 2013), but would avoid problem shifting to the future (Lebailly et al. 2014). Berntsen et al. (2010) say that if goals for impacts are set lower, the TH should become shorter because it is assumed that there shall be continuous improvements and so the target year for the reduced goals would come earlier. Nevertheless, action orientation in the TH identification can also lead to gaming incentives. A temporal cutoff encourages emission shifting to the end of the assessment period and temporal emission storage without consumption reduction (Brandão and Levasseur 2011). For example, a fixed TH leads to the incentive for carbon capture and storage to store the carbon until 1 year after the end of assessment (Brandão et al. 2013). According to Fearnside (2001), because of the risk of gaming, an assessment should consider actions of actors and possible innovations in this field after the TH. Action orientation can also lead to counterintuitive measures. If new artificial systems (e.g., fast growing biomass) proved to be more efficient in binding $\mathrm{CO}_{2}$ than natural systems, long THs would lead to the conclusion that nature (forests) should be removed. This would also depend on the inclusion and assessment of other impact categories (Soimakallio et al. 2015).

\section{Derivation of TH by measurement orientation}

Instead of thinking of incentives for actions, THs can also be derived from requirements for exact measurements. Measuring dynamics in the inventory would be useless if the TH is infinite (Dyckhoff and Kasah 2014). Udo de Haes et al. (1999) stated that it is sufficient if a TH includes most of the impact, so that in some cases 500 years or 10,000 years would be enough for radioactivity concerns. According to Brandão et al. (2013), the TH should be long enough so that the assessed impact is no longer relevant. The TH could be calculated based on reaching a steady state in fate models for emissions, as in the case of leakage from landfills (Finnveden 1999). Kirkinen et al. (2008) say that THs should be oriented on assumed turning points in nature, e.g., for global warming, and therefore be rather short. De Rosa et al. (2017) say that the TH must fit the used indicators. For example, if sea level rise was applied as an indicator for global warming, a short TH would be inappropriate. Almeida et al. (2015) chose certain THs because they are necessary for the GWP metric. However, Berntsen et al. (2010) state that "the target determines the metric and not the other way around; one should first define the target, and then choose an appropriate 
Table 1 Reasons for short and long $\mathrm{TH}$ of the assessment

\begin{tabular}{|c|c|}
\hline Reasons for short $\mathrm{TH}$ & Reasons for long $\mathrm{TH}$ \\
\hline - Long THs can overestimate impacts & - Short THs can underestimate impacts \\
\hline - Long THs make short term actions less favorable & $\begin{array}{l}\text { - Short THs place weighting on short-term impact } \\
\text { categories }\end{array}$ \\
\hline $\begin{array}{l}\text { - Long THs often ignored because of higher complexity } \\
\text { and uncertainty }\end{array}$ & - Appreciate intergenerational equality \\
\hline - General short time preference of people & $\begin{array}{l}\text { - Short THs lead to wrong incentives in year } \mathrm{X}+1 \\
\rightarrow \text { gaming }\end{array}$ \\
\hline $\begin{array}{l}\text { - Long THs ignore urgency of problems, excuse } \\
\text { non-action } \\
\text { - Possibility of future mitigation technology }\end{array}$ & - Avoids problem shifting to the future \\
\hline $\begin{array}{l}\text { - THs should fit political goals which are usually } \\
\text { short-term }\end{array}$ & \\
\hline
\end{tabular}

metric and a consistent time horizon." Nevertheless, the metric plays a role only if static LCA is applied. Then short THs could underestimate impacts and long THs could overestimate impacts because long-term emissions are summed at the beginning. Small amounts of emissions distributed over a long time can have a much lower impact than the same amount over a short time (Kendall 2012). Therefore, if long THs are set, a dynamic LCA should be applied. This is also emphasized by Bakas et al. (2015) who show on the example of long-term heavy metal leaches from landfills that a static LCA significantly overestimates the actual toxicity of those emissions. Mallapragada and Mignone (2017) consider it useful to apply fixed THs for midpoint indicators and fixed endpoints (in time) for endpoint indicators. A certain TH is required if long- and short-term emissions are assessed together; otherwise, the long-term emissions would marginalize those which are short-term in infinite or long THs.

An interesting approach for LCA is the "time-dominance principle" (Dyckhoff and Kasah 2014). If there is a decision to be made between some alternatives and some of them are less favorable within any $\mathrm{TH}$ than others, these alternatives are called "dominated." Therefore, TH considerations must not be implemented for the dominated ones. The decision problem is reduced to the remaining alternatives. Hauschild et al. (2008) apply two THs: 100 years and after 100 years. They assess emissions of the first 100 years, as is commonly done, and introduce a new indicator "stored toxicity" which can also be applied to other impact categories.

Reasons for short and long THs are summarized in Table 1.

\section{Equivalence of $\mathrm{TH}$ and discounting}

For many authors, the discussions around adequate THs for assessments and adequate discount rates are equivalent, e.g., see Boucher (2012) or Almeida et al. (2015). For Fearnside et al. (2000) and $\mathrm{Hu}$ (2018), THs and discounting are both time preference schemes. Mallapragada and Mignone (2017) state that a TH is only a substitute for explicit discounting. For Fearnside et al. (2000), they are equivalent, but the $\mathrm{TH}$ is easier to explain to the public.

\subsubsection{Temporal weighting/discounting}

"Discounting is the mechanism by which a value for time is normally translated into economic decision-making" (Fearnside et al. 2000). For different reasons, discounting is also proposed in LCA. Fearnside (2002) explains that discussions about applying discounting for the global warming assessment began already in the early 1990s but the IPCC instead adopted the procedure of time horizons. Fearnside (2002) criticizes that the THs suggested by the IPCC, 25, 100 , and 500 years, are unrealistic options because 25 years would obviously be too short and 500 years too long, meaning most people chose the 100-year TH. We classified findings on discounting as follows:

\section{Subjectivity of discounting}

Similar to our findings on THs, discount functions and rates are regarded as a non-consensual (Almeida et al. 2015), value-laden (Brandão and Levasseur 2011), and ethical (Levasseur et al. 2012) choice. As LCA is a value-based decision instrument, it should apply discounting (Hellweg et al. 2003), which would make it a more "business-like" decision instrument (Yuan et al. 2015). Another term for expressing subjectivity is "time preference." Many authors claim that time preference is the main reason for discounting (Levine et al. 2007; O'Hare et al. 2009; Fearnside et al. 2000). Fearnside (2002) explains time preference with the mortality of people. According to Hellweg et al. (2003), there is ethical consensus that discounting based purely on a time preference is immoral and should not be applied in LCA, but can be regarded by decision makers. Fearnside et al. (2000) suggest 
the term "immediate emission equivalent" instead of discounted emission because the term "discounting" would describe the calculation of the net present value of money. They further describe "distortions" in the assessment if discounting is disregarded over THs longer than 100 years. Generally, a decision about discounting in LCA cannot be avoided, as a decision for a discount rate of zero would also be a decision that one would have to make, which should be justified in the same way a decision for any other rate would be (Fearnside et al. 2000). For the calculation of discount rates, Bakas et al. (2015) proposed applying different scenarios based on different sociocultural types of people. In the cited cultural theory (Hofstetter et al. 2000), there are the already discussed four different archetypes of people with different perceptions of time or risk, which can result in different discount rates for them. Cultural theory is already applied by impact assessment tools like Recipe and EcoIndicator99 for setting different THs and weighting schemes according to the different cultural perspectives but they are not applied to discounting there (Hauschild et al. 2018). The reliance on different perceptions is also assumed by Field et al. (2001), who state that decisions on discount rates should be made at the end by the decision maker and not already by the LCA maker. As explained in the TH section, it is also valid for discounting that delaying emissions only makes sense if there is a value for time (Brandão and Levasseur 2011). Due to the inherent subjectivity, scenario or sensitivity analysis is suggested by many authors (Herzog et al. 2003; Weitzman 1998; Yuan et al. 2015).

\section{Importance of an accurate discount rate}

Yuan et al. (2015) describe a high influence of the discount rate on the outcome of an LCA. Even small rates around 1\% marginalize impacts over just a few decades (Fearnside 2002). Bakas et al. (2015) propose a small rate near $0 \%$ as the rate is very decisive. According to Yuan et al. (2009), discounting should be handled very conservatively because an underestimation of impacts would be more critical than an overestimation.

\section{Discounting for monetary reasons}

One obvious reason for discounting is that environmental damages or their prevention cause costs, and costs can be discounted. Even if there is currently no reliable monetization mechanism available for certain emissions, assuming that impact and monetary value are congruent, impact can be discounted in the same way as the monetary value (Kendall et al. 2009; Wang et al. 2018). The discount rate depends on the overall change in wealth and the change of the marginal utility of that change (Fearnside et al. 2000) and inflation (O'Hare et al. 2009; Levine et al. 2007). The latter authors assume that monetized damage will be reduced in the future as a result of new technologies to cope with it. The social discount rate, a measure used in cost-benefit analysis that also assumes economic growth, can also be applied in LCA (Richards 1997; Wang et al. 2018). This means that discounting is not only a temporal but also a spatial problem, as economic growth is not evenly distributed over the world. Fearnside (2002) criticizes this by saying that discounting should not be applied to permanent losses, like losses in biodiversity. According to Hellweg et al. (2003), discounting with monetized damages assumes that future generations would be satisfied with monetary compensation, which is not necessarily true. They state that the discount rate depends on opportunity costs that originate from alternatives and economic growth and that it can become negative in scenarios with economic decline.

\section{Time-dependent discount rates}

For several reasons, a declining discount rate over time can be assumed. Boucher (2012) discusses a discount rate declining from 3.5 to $1 \%$ after 30 years because of the change from individual to intergenerational discounting after that time and due to growing uncertainty. Weitzman (1998) states that exponential discounting would not reflect the real opinion of people regarding the weight of future emissions from a certain point of time on. For example, an event in 300 years would not be less important than an event in 400 years. He also proposes a declining discount rate. For long-term impacts, different discount rates should be calculated, with the lowest discount rate being applied as the final discount rate. Fearnside (2002) introduces a "generation weighted index" where the discount rate declines after every generation for four generations. According to Richards (1997), the change of marginal damage by the emissions must be taken into consideration. Rising marginal damage should lead to a declining discount rate over time. The mixing of damage functions and discounting, i.e., physical discounting, is rejected by others.

\section{Physical discounting}

Hellweg et al. (2005) also apply discounting as a measure of dynamic characterization and normalization. The discount rate is derived from the assumed changing background concentration. In contrast, for O'Hare et al. (2009), "the discounting model applies to costs and benefits, not to physical phenomena that generate them, unless their economic value is otherwise stable over time." They recommend not discounting physical quantities. Brandão and Levasseur (2011) differentiate between discounting for economic and social reasons and physical discounting on which the $\mathrm{TH}$ is based on. 


\section{Chances, risks and uncertainty}

For Udo de Haes et al. (1999) and Yuan et al. (2009), the uncertainty whether future impacts will happen is a factor for discounting. This can be influenced by technological advances or simply by a reduced life cycle, e.g., due to accidents (Yuan et al. 2009). Contrary to that, according to Hellweg et al. (2003), discounting because of uncertainty should be avoided and uncertainty should be considered in the "damage prediction" (characterization). Uncertainty can lead to higher or lower discount rates, depending on uncertain positive or negative effects.

\subsubsection{Temporal resolution of the inventory}

A lot of information on the modeling of a dynamic inventory (DI) based on natural scientific phenomena, like growth of biomass, spatial distribution of emissions over time, or fate mechanisms of chemicals in nature, can be found in literature. Most of these are excluded for this review because we are focused only on basic principles.

The basic principle, the "dynamic" or "time-dependent" LCI, is defined by Tiruta-Barna et al. (2016) as applying a sort of future prediction or higher temporal resolution. A dynamic LCI is a premise for exact discounting (Yuan et al. 2015) and advanced indicators for dynamic characterization. For example, daytime is relevant for the assessment of albedo effects in global warming (Almeida et al. 2015). LCAs derived from static models have a temporal bias (Guo and Murphy 2012), e.g., because simple accumulation of emissions data from small emissions over long THs lead to an impact overestimation (Bakas et al. 2015). The temporal resolution can have a decisive influence on the outcome of an LCA (Beloin-Saint-Pierre et al. 2016). Shimako et al. (2018) show that the assessment of toxicity is highly influenced by the temporal resolution while it does not play a role in the assessment of global warming. A dynamic LCI can include temporal fate mechanisms of emissions (Herrchen 1998; Yuan et al. 2015; Lebailly et al. 2014; Shimako et al. 2017). Furthermore, it is needed if, rather than a single product, a fleet of products is assessed because that fleet rises after market entrance and will eventually decline later (Levine et al. 2007). As it can become very time consuming to build a dynamic LCI, literature proposes some simplifications. According to Beloin-Saint-Pierre et al. (2016), it is not necessary that the whole inventory be dynamic, especially if there are many small emissions. In their article, they modeled $85 \%$ of the inventory in a dynamic way and positioned the remaining emissions at the starting point so that their effects are assessed over the whole life cycle, which can be considered a conservative approach. Hu (2018) did not calculate a completely steady temporal LCI but divided the life cycle into different sequences like construction, operation, renovation, and second operation, so that the temporal resolution is low and given by the sequences, but the resulting LCA is still more accurate than a static LCA. Temporally differentiated data often cannot be predicted exactly, but can be modeled by mathematical functions with time dependencies. This may be recommended if there is a direct physical correlation between the functional unit and the inventory (Moura Costa and Wilson 2000; Huijbregts et al. 2001). Statistical functions can be applied to assess uncertainty, such as product failures or accidents (Field et al. 2001; Wang et al. 2018). Another proposed simplification is the "time resolved LCA" where the LCI is not measured but simulated based on historical data or simple simulation. Temporal effects can be regarded without the need for complex measurements (Zimmermann et al. 2014). In more complex cases, a scenario analysis of the LCI can be carried out (Zimmermann et al. 2015). More complex prediction methods are suggested by Su et al. (2017): demand-supply models, complex adaptive systems, and Markov chains for short-term issues, and scenario analysis, query, investigation, and estimation for long-term issues, literature review, and simulation of user behavior. A modeling approach based on possible paths a product can take during its life cycle is introduced by Yuan et al. (2009). During production, a product can take fast paths under optimal circumstances or slow paths when there are errors or loops due to inferior quality. The path approach is also chosen by BeloinSaint-Pierre et al. (2014) in their "enhanced structural path analysis." It is used to build a temporal differentiated LCI without creating much data because the same processes are reused multiple times in different process steps or products. Such an LCI would be based on processes and not only on (intermediate) product data, which would reduce the overall data requirement. Nevertheless, reducing the complexity of a dynamic LCI remains difficult. There are interactions in process and supply chain dynamics as well as loop paths. TirutaBarna et al. (2016) define two main challenges. First, foreground processes can be modeled or measured precisely, but background processes in the supply chain lack certain data and adequate temporal assessment. There must be a supply model between foreground and background processes that models the supply schedule and existing delays between the processes. Second, finding the best trade-off between accuracy and feasibility can be challenging. They propose an algorithm for calculating dynamic LCI based on a process and supply network. In the face of all these complexity, Almeida et al. (2015) question the usefulness of a dynamic LCI because it is complex, not fully available in LCA software, and harder to communicate than a static approach. Furthermore, it does not solve temporal issues like the TH/cut-off issue. This criticism shows that temporal issues must be addressed in an integrated way. For example, Tiruta-Barna et al. (2016) criticize that the methodological literature generally addresses 
either the dynamic inventory or the dynamic characterization issue but rarely both, suggesting that links remain missing.

\subsubsection{Time-dependent characterization}

For Collinge et al. (2013), the inventory is a model of the "technosphere" while the characterization models the "biosphere" affected by it. Laratte et al. (2014) call an LCA with a dynamic LCI but static characterization factors (CF) a "partly dynamic LCA." The use of dynamic CFs make it a "fully dynamic LCA," which is preferred because of its higher accuracy. This is confirmed by Menten et al. (2015) in a comparative analysis. According to Levasseur et al. (2013), it would be inconsistent not to apply dynamic CF on a dynamic LCI because emissions near the end of the TH would have a lower weighting than earlier emissions, but the inconsistency issue is very dependent on the interpretation of what exactly is meant by the TH, as explained in the TH section above. For example, if the TH of the whole assessments ends 100 years after the first emission, then only this first emission is fully weighted by a GWP100 and later emissions would have to be cut. If the TH ends 100 years after the last emission, then no emission would have to be cut when this static indicator is applied. Either way, dynamic CFs are dependent on the TH of the assessment because in a short TH less impact can happen, depending on the impact category (Guo and Murphy 2012; Lebailly et al. 2014; Collinge et al. 2013). According to Bakas et al. (2015), such time-dependent CFs do not challenge the principle of intergenerational equality, only the setting of TH and discounting do. Conversely, dynamic characterization can be used to set the TH after which only little impact remains (Levasseur et al. 2013). We identified two main reasons for dynamic characterization. First, as most impacts depend on a certain concentration, which is not only defined by the assessed emissions but also by the background concentration, a changing background concentration over time must be regarded (Bakas et al. 2015; Collinge et al. 2013). The dependency on background concentration can be non-linear, e.g., because of certain thresholds (Hellweg et al. 2005), but there can also be an impact limit through saturation (Herzog et al. 2003). This leads to the second reason for dynamic $\mathrm{CFs}$, the changing sensitivity of the ecosystem over time (Almeida et al. 2015; Bakas et al. 2015; Collinge et al. 2013). Hellweg et al. (2005) mention a threshold-weighting factor depending on the "magnitude of exceedance of noeffect levels and, in case of dynamic modeling, on the time period of exceedance". Bakas et al. (2015) state that because of the changing ecosystem, not only the inventory but also the impacted system should be modeled dynamically. This ecosystem includes people. The changing distribution of exposed populations, such as the age distribution, should be included in a dynamic model (Collinge et al. 2013).
Regardless, dynamic CFs are currently not available for most impact categories. According to Collinge et al. (2013), there are dynamic $\mathrm{CFs}$ for global warming and photochemical ozone and, under local premises, also for eutrophication, acidification, and ozone depletion. Van Zelm et al. (2007) calculate a dynamic $\mathrm{CF}$ for acidification and Schwietzke et al. (2011) discuss the cumulative radiative forcing as a dynamic CF instead of GWP for global warming. As in the other temporal issues, there are strategies for simplification of dynamic characterization. For delaying global warming, there is the ton-year approach that declares how many tons of $\mathrm{CO}_{2}$ are avoided over a certain number of years compared with an alternative (Fearnside et al. 2000), but this cannot really be considered a dynamic impact measurement (Moura Costa and Wilson 2000). Bakas et al. (2015) and Hauschild et al. (2008) propose "stored toxicity," or generalized stored impact, for emissions exceeding 100 years or a certain $\mathrm{TH}$ and assign them an indirect weighting in relation to the value of the corresponding short-term indicator. Kendall et al. (2009) introduce a time correction factor that has to be multiplied with GWP and gives early emissions a higher weight than emissions near the TH of assessment. The kinetics of the emissions must be considered as well, particularly when materials change due to external effects, e.g., the generation of metabolites with an increased or reduced toxic effect. This would favor carbon capture and storage measures. Kendall (2012) calls the same idea "time adjusted global warming potential". Nevertheless, Kendall and Price (2012) suggest a fully dynamic CF like cumulative global warming instead of a time adjusted GWP. The difference between a CF that is only dependent on the $\mathrm{TH}$ and a fully dynamic $\mathrm{CF}$ as a function of the inventory, impact mechanism, and the time axis is also explained by Shimako et al. (2017), who prefer the latter due to its higher accuracy. Another index that must be multiplied with the GWP is the GWPbio (Cherubini et al. 2011). It is introduced as a $\mathrm{CF}$ for assessing biogenic $\mathrm{CO}_{2}$ emissions, which contribute to the global warming because of atmospheric decay, depending on the rotation period of the biomass species.

\subsubsection{Dynamic weighting}

Fearnside (2002) suggests dynamic weighting for the assessment of the changing distribution of age in society, presuming that people of different ages have different preferences. Su et al. (2017) state that weighting could change over time, depending on the weighting mechanism. If monetization is applied, future weighting factors could be assessed based on shadow prices or green tax predictions. If distance-to-target measures are applied, current goals of environmental protection policy could be brought up (Levasseur et al. 2013). 


\subsubsection{Time-dependent normalization}

Time-dependent normalization is rarely dealt with in the literature. It is suggested by Cherubini et al. (2012), Herrchen (1998), and Hellweg et al. (2005) because changing future background concentrations can lead to different outcomes in the normalization of impacts. As the future background concentration is difficult to assess, Herrchen (1998) suggests estimating it by assuming that current political goals or international emission limiting contracts will be fulfilled or by estimating remaining amounts of resources that cause the specific emissions. Hauschild et al. (2008) apply different normalization factors for their near-time toxicity indicator and their long-term stored toxicity indicator, which could be assigned to other impact categories that "store" impacts over long THs. Discounting of impacts can be regarded as a kind of normalization if monetizable damage is opposed to economic growth or inflation (Hellweg et al. 2003).

\section{Discussion}

Our main finding is that there are different THs with interdependencies with other temporal issues. The TH of the whole assessment, defined in goal and scope, is the longest of the different THs. Within it, there is a TH of the inventory and a $\mathrm{TH}$ of its impact characterization. It must be regarded as inconsistency if the THs of inventory or characterization exceed the $\mathrm{TH}$ of the assessment. According to many authors, the $\mathrm{TH}$ of assessment is directly linked to the discounting issue. The consensus in literature suggests that setting THs and setting discount functions is equivalent, because one can calculate a discount rate for every $\mathrm{TH}$ so that the integrated impacts over time are the same. Some authors regard the TH of the assessment as a simplification of discounting with a $0 \%$ rate at the beginning and a $100 \%$ rate after the TH. This is in direct contrast with another consensus in the literature-when the discount function is time dependent, no author calculates with rising discount rates over time, but instead always with falling discount rates. THs of the assessment and discount functions are regarded as subjective or even arbitrary. This is unsatisfactory for scientists. There are some approaches that offer simplification of this issue, like the time dominance principle, where alternatives that have a worse ecological performance over every $\mathrm{TH}$ are sorted out. In addition, the TH can be regarded as a dependent variable and plotted in a graph where a decision maker can see the general influence of the TH on the assessment outcome. The decision maker or the purpose of the LCA seems to be the key variable for calculating an adequate $\mathrm{TH}$. The problem can be approached by the social discounting theory or by the social theory that divides people into different moral classes. Nevertheless, many authors propose sensitivity or scenario analysis on THs and discounting.
From an action-oriented view, short THs are preferred because long THs would not weight short-term actions highly enough and would offer an excuse for inaction today. From a measurement perspective, long THs would include more emissions and would be fairer to future generations.

The $\mathrm{TH}$ of the inventory is the second $\mathrm{TH}$ to be determined. It is usually equivalent to the length of the life cycle of the product, but should be longer if significant emissions after the end of life occur. There is consensus that an LCA becomes more accurate the higher the temporal resolution of the LCI is, regardless of whether it is assessed with static or dynamic characterization. For simplification, only important parts of the LCI could have a temporal resolution or parts of the dynamic LCI could be simulated, including fate mechanisms.

The third TH is the TH of the characterization. In a wellknown characterization factor, the 100 -year GWP, a fix TH is applied. Time-dependent characterization is rarely applied but available for some impact categories. To ensure that the TH of characterization does not exceed the TH of the assessment, there are time adjustment factors available for the GWP. They reduce the GWP relative to the TH of assessment. Another approach is to assess the remaining impact after the TH of assessment in a second indicator "stored emissions."

Changing weighting factors over time could incorporate change in the composition of the society, such as rising average age. Time-dependent normalization is proposed by some authors. Nevertheless, one should consider the risk of assuming declining background concentrations because actions for environmental protection would lose incentives today if a general decline in pollution was presumed. If everyone would calculate in this way, the declining pollution may never actually manifest because there would be no argument for action according to life cycle assessments.

Finally, assessing environmental impacts dynamically could be interesting for the emitters. Usually, impacts are lower when assessed in this way because later emissions are assessed with lower impacts and threshold or dosedependent impacts may not appear at all.

\section{Limitations}

The main limitation of our review is to be found in the search terms and strategy. Unless we think that our search terms were very broad, other terms may have yielded additional helpful results, and searching in other databases may have identified other papers. Ecology-specific databases like Environment Complete or Sustainability Reference Center were not available to us. Furthermore, we could have missed results during the selection by titles. Nevertheless, by including referred literature from our search results ("snowball search"), we reduced the possibility of missing important literature. Our procedure only to include literature with original contributions to 
temporal issues leaves room for interpretation so that our bibliographic analysis may be weaker than the content analysis. According to Berrang-Ford et al. (2015), more complex research questions often necessitate a combination of search approaches and more flexible or iterative search designs, like forward and backward citation tracking and expert-sourced information. As a relatively wide research question is always complex and because of the wide distribution of interesting ideas on temporal issues only as secondary content in many papers, a deeper review could make use of a more complex search strategy.

\section{Open questions}

Dividing the TH issue into three different THs makes the temporal issues overall more comprehensive, but there is no consensus in the literature as to whether it must be regarded as an inconsistency if the different THs have different lengths or ends. For example, it is questionable if applying a GWP100 in a dynamic LCI is inconsistent because later emissions would be weighted too high and early emissions too low. This is an open field for further considerations. Another open field for research is the determination of the TH of assessment or the discount function. Currently, the best solutions are to let the reader of the LCA (the decision maker) decide by producing sensitivities, scenarios, or TH-dependent impact graphs. One can argue that LCA as a decision instrument should not have this degree of freedom for interpretation, but should instead deliver exact results. Discount functions, possibly depending on goal and scope, could be derived from the social discount rate, cultural theory, equivalencies to current practice in the $\mathrm{TH}$ determination, and other sources that need to be identified. We agree with Yuan et al. (2009): "Although we recognize the need to develop proper discounting methods, such endeavors deserve a more thorough analysis." We think that our review can contribute to the development of practical frameworks and the enhancement of ISO norms for LCA with respect to temporal issues. It would be of theoretical interest to analyze more cases where decisions based on LCAs, which were made in the past without considering temporal issues, would have come to a different outcome if they were considered.

\section{Conclusion}

We conducted the first systematic review on temporal issues in LCA and conclude the following findings:
1. There are six direct temporal issues: time horizons, discounting, dynamic inventory, dynamic characterization, dynamic normalization, and dynamic weighting.

2. Not considering them in LCA is a simplification that in some cases can have decisive influence on the outcome of LCA, potentially leading to wrong decisions.

3. There is consensus in literature that the application of a dynamic inventory or a dynamic characterization improves the accuracy of LCA. The creation of a dynamic inventory can be elaborate for the LCA practitioner. Like the cut-off criteria that are defined in the goal and scope part, there could be criteria for the inventory that define which important parts should have a temporal resolution while the rest is only summed up. The knowledge on fate mechanisms and dynamic characterization mechanisms is growing and can be integrated gradually to LCA in the future.

4. A big concern with decisive influence on the LCA outcome is the setting of time horizons. There are three TH. The TH of the assessment is the temporal system barrier. It is defined in the goal and scope section like the other system barriers. There is a debate on the correct length of this TH and there are good reasons for longer and shorter THs. We think, the salomonic judgment would state: It depends on goal and scope. The TH of the assessment should fit to the interests of the stakeholders of the individual LCA. It cannot be standardized in general by the ISO norm but there may be standards for certain branches or labels to ensure comparability.

5. The inventory also has a certain $\mathrm{TH}$, which is the period for that emissions are registered. Parallel and usually continuing after the $\mathrm{TH}$ of the inventory is the $\mathrm{TH}$ of impacts by this inventory. The maximum TH of the inventory is the period in which emissions occur and the maximum $\mathrm{TH}$ of the impacts is the period during that the areas of protection are damaged. However, if the TH of the assessment ends earlier then there has to be a cut-off. In our opinion, it is inconsistent to characterize a dynamic inventory with a static characterization if that would exceed the TH of the assessment. For example, if the TH of assessment is 100 years and there is a yearly subdivided inventory, then the climate gas emissions in year 99 cannot be characterized by a 100 -year GWP but only by a 1 -year GWP. Otherwise, the temporal system barrier of the assessment would be exceeded.

6. Discounting is partly misunderstood in literature. Some authors rightly criticize "physical discounting," the application of a discount-like function as replacement for dynamic characterization or fate mechanisms. Nevertheless, there is consensus that setting a $\mathrm{TH}$ of the assessment and discounting impact would be equivalent. We do not follow this interpretation. There can be both a temporal system barrier and a 
changing value of impacts over time within it and both may follow their own logics.

7. Time-dependent weighting and normalization factors are rarely mentioned in literature. That may mean that there is no need for them because weighting is conducted in the viewpoint of the current stakeholders of the LCA and time-dependent normalization might be misleading. If one would suppose a declining pollution in the world from the outset, then there is a reduced incentive to act and the declination may never happen. Excluding those two rather theoretical direct temporal issues, only four relevant temporal issues remain.

Acknowledgments Open Access funding provided by Projekt DEAL. We thank BASF SE and Technische Universität Dresden PRISMACentre for Sustainability Assessment and Policy for enabling this research by granting a $\mathrm{PhD}$ scholarship.

Open Access This article is licensed under a Creative Commons Attribution 4.0 International License, which permits use, sharing, adaptation, distribution and reproduction in any medium or format, as long as you give appropriate credit to the original author(s) and the source, provide a link to the Creative Commons licence, and indicate if changes were made. The images or other third party material in this article are included in the article's Creative Commons licence, unless indicated otherwise in a credit line to the material. If material is not included in the article's Creative Commons licence and your intended use is not permitted by statutory regulation or exceeds the permitted use, you will need to obtain permission directly from the copyright holder. To view a copy of this licence, visit http://creativecommons.org/licenses/by/4.0/.

\section{References}

Adam B (1998) Timescapes of modernity. The environment and invisible hazards. Routledge, London (Global environmental change series)

Almeida J, Degerickx J, Achten WMJ, Muys B (2015) Greenhouse gas emission timing in life cycle assessment and the global warming potential of perennial energy crops. Carbon Manag 6(5/6):185195. https://doi.org/10.1080/17583004.2015.1109179

Angelakoglou K, Gaidajis G (2015) A review of methods contributing to the assessment of the environmental sustainability of industrial systems. J Clean Prod 108:725-747. https://doi.org/10.1016/j.jclepro. 2015.06.094

Bakas I, Hauschild MZ, Astrup TF, Rosenbaum RK (2015) Preparing the ground for an operational handling of long-term emissions in LCA. Int J Life Cycle Assess 20(10):1444-1455. https://doi.org/10.1007/ s11367-015-0941-4

Beloin-Saint-Pierre D, Heijungs R, Blanc I (2014) The ESPA (enhanced structural path analysis) method. A solution to an implementation challenge for dynamic life cycle assessment studies. Int J Life Cycle Assess 19(4):861-871. https://doi.org/10.1007/s11367-014-0710-9

Beloin-Saint-Pierre D, Levasseur A, Margni M, Blanc I (2016) Implementing a dynamic life cycle assessment methodology with a case study on domestic hot water production. J Ind Ecol:11281138. https://doi.org/10.1111/jiec.12499

Berntsen T, Tanaka K, Fuglestvedt JS (2010) Does black carbon abatement hamper CO2 abatement? Clim Chang 103(3-4):627-633. https://doi.org/10.1007/s10584-010-9941-3

Berrang-Ford L, Pearce T, Ford JD (2015) Systematic review approaches for climate change adaptation research. Reg Environ Chang 15(5): 755-769. https://doi.org/10.1007/s10113-014-0708-7

Boucher O (2012) Comparison of physically- and economically-based CO2-equivalences for methane. Earth Syst Dyn 3(1):49-61. https://doi.org/10.5194/esd-3-49-2012

Brandão M, Levasseur A, Kirschbaum MUF, Weidema BP, Cowie AL, Jørgensen SV, Hauschild MZ, Pennington DW, Chomkhamsri K (2013) Key issues and options in accounting for carbon sequestration and temporary storage in life cycle assessment and carbon footprinting. Int J Life Cycle Assess 18(1):230-240. https://doi. org/10.1007/s11367-012-0451-6

Brandão M, Levasseur A (2011) Assessing temporary carbon storage in life cycle assessment and carbon Footprinting. Report JRC 63225

Brander M (2017) Comparative analysis of attributional corporate greenhouse gas accounting, consequential life cycle assessment, and project/policy level accounting. A bioenergy case study. J Clean Prod 167:1401-1414. https://doi.org/10.1016/j.jclepro.2017.02.097

Charlton C, Howell B (1992) Life cycle assessment. A tool for solving environmental problems? Eur Environ 2(2):2-5. https://doi.org/10. 1002/eet.3320020203

Cherubini F, Guest G, Strømman AH (2012) Application of probability distributions to the modeling of biogenic $\mathrm{CO} 2$ fluxes in life cycle assessment. GCB Bioenergy 4(6):784-798. https://doi.org/10.1111/ j.1757-1707.2011.01156.x

Cherubini F, Peters GP, Berntsen T, Strømman AH, Hertwich E (2011) $\mathrm{CO} 2$ emissions from biomass combustion for bioenergy. Atmospheric decay and contribution to global warming. GCB Bioenergy 3(5):413-426. https://doi.org/10.1111/j.1757-1707. 2011.01102.x

Collinge WO, Landis AE, Jones AK, Schaefer LA, Bilec MM (2013) Dynamic life cycle assessment. Framework and application to an institutional building. Int J Life Cycle Assess 18(3):538-552. https://doi.org/10.1007/s11367-012-0528-2

Colocousis CR, Rebellon CJ, Smith N, Sobolowski S (2017) How long can we keep doing this? Sustainability as a strictly temporal concept. J Environ Stud Sci 7(2):274-287. https://doi.org/10.1007/s13412015-0355-4

Dones R, Heck T, Emmenegger F, Mireille, Jungbluth N (2005) Life cycle inventories for the nuclear and natural gas energy systems, and examples of uncertainty analysis (14 pp). Int J Life Cycle Assess 10(1):10-23. https://doi.org/10.1065/lca2004.12.181.2

Dyckhoff H, Kasah T (2014) Time horizon and dominance in dynamic life cycle assessment. J Ind Ecol 18(6):799-808. https://doi.org/10. 1111 /jiec. 12131

ISO 14040:2009-11: Environmental management - Life cycle assessment - Principles and framework

Fearnside PM (2001) Why a 100-year time horizon should be used for global warming mitigation calculations. Mitig Adapt Strateg Glob Chang 2002(7):19-31

Fearnside PM (2002) Time preference in global warming calculations: a proposal for a unified index. Ecol Econ 2002(41):21-31

Fearnside PM, Lashof DA, Moura-Costa P (2000) Accounting for time in mitigating global warming through land-use change and forestry. Mitig Adapt Strateg Glob Chang 5(3):239-270. https://doi.org/10. 1023/A:1009625122628

Field F, Kirchain R, Clark J (2001) Life-cycle assessment and temporal distributions of emissions: developing a fleet-based analysis. J Ind Ecol 4(2)

Fink A (2014) Conducting research literature reviews. From the internet to paper, 4th edn. SAGE, Los Angeles 
Finnveden G (1999) Methodological aspects of life cycle assessment of integrated solid waste management systems. Resour Conserv Recycl 26(3-4):173-187. https://doi.org/10.1016/S0921-3449(99) 00005-1

Finnveden G (2000) On the limitations of life cycle assessment and environmental systems analysis tools in general. Int J Life Cycle Assess 5(4):229-238. https://doi.org/10.1007/BF02979365

Finnveden G, Hauschild MZ, Ekvall T, Guinée J, Heijungs R, Hellweg S, Koehler A, Pennington D, Suh S (2009) Recent developments in life cycle assessment. J Environ Manag 91(1):1-21. https://doi.org/10. 1016/j.jenvman.2009.06.018

Guinée JB, Heijungs R, Huppes G, Zamagni A, Masoni P, Buonamici R et al (2011) Life cycle assessment. Past, present, and future. Environ Sci Technol 45(1):90-96. https://doi.org/10.1021/es101316v

Guo M, Murphy RJ (2012) LCA data quality. Sensitivity and uncertainty analysis. Sci Total Environ 435-436:230-243. https://doi.org/10. 1016/j.scitotenv.2012.07.006

Hauschild M, Olsen SI, Hansen E, Schmidt A (2008) Gone...but not away - addressing the problem of long-term impacts from landfills in LCA. Int J Life Cycle Assess 13(7):547-554. https://doi.org/10. 1007/s11367-008-0039-3

Hauschild MZ, Rosenbaum RK, Olsen SI (eds) (2018) Life cycle assessment. Theory and practice. Springer, Cham

Held M (2016) Sustainable development from a temporal perspective. Time Soc 10(2-3):351-366. https://doi.org/10.1177/ 0961463X01010002011

Hellweg S, Hofstetter TB, Hungerbühler K (2003) Discounting and the environment should current impacts be weighted differently than impacts harming future generations? Int J Life Cycle Assess 8(1): 8-18

Hellweg S, Hofstetter TB, Hungerbühler K (2005) Time-dependent lifecycle assessment of slag landfills with the help of scenario analysis. The example of Cd and Cu. J Clean Prod 13(3):301-320. https://doi. org/10.1016/j.jclepro.2004.02.016

Hellweg S, Milà i Canals L (2014) Emerging approaches, challenges and opportunities in life cycle assessment. Science (New York, NY) 344(6188):1109-1113. https://doi.org/10.1126/science.1248361

Herrchen M (1998) Perspective of the systematic and extended use of temporal and spatial aspects in LCA of long-lived products. Chemosphere 37(2):265-270. https://doi.org/10.1016/S00456535(98)00045-9

Herzog H, Caldeira K, Reilly JM (2003) An issue of permanence: assessing the effectiveness of temporary carbon storage. Clim Chang 59:293-310

Hofstetter P, Baumgartner T, Scholz RW (2000) Modelling the valuesphere and the ecosphere. Integrating the decision makers' perspectives into LCA. Int J Life Cycle Assess 5(3):161-175. https://doi.org/10.1007/BF02978618

Hu M (2018) Dynamic life cycle assessment integrating value choice and temporal factors - a case study of an elementary school. Energy Build 158:1087-1096. https://doi.org/10.1016/j.enbuild.2017.10. 043

Huijbregts MAJ, Guinée JB, Reijnders L (2001) Priority assessment of toxic substances in life cycle assessment. III Export of potential impact over time and space. Chemosphere 44(1):59-65. https:// doi.org/10.1016/S0045-6535(00)00349-0

Huijbregts MAJ (1998) Application of uncertainty and variability in LCA. Part I A general framework for the analysis of uncertainty and variability in life cycle assessment. Int $\mathrm{J}$ Life Cycle Assess 3(5):273-280

International Reference Life Cycle Data System (ILCD) (2010) Handbook. General guide for life cycle assessment: detailed guidance, 1st edn. Publications Office (EUR (Luxembourg), Luxembourg, p 24708
Kendall A (2012) Time-adjusted global warming potentials for LCA and carbon footprints. Int J Life Cycle Assess 17(8):1042-1049. https:// doi.org/10.1007/s11367-012-0436-5

Kendall A, Chang B, Sharpe B (2009) Accounting for time-dependent effects in biofuel life cycle greenhouse gas emissions calculations. Environ Sci Technol 43(18):7142-7147

Kendall A, Price L (2012) Incorporating time-corrected life cycle greenhouse gas emissions in vehicle regulations. Environ Sci Technol 46(5):2557-2563. https://doi.org/10.1021/es203098j

Kirkinen J, Palosuo T, Holmgren K, Savolainen I (2008) Greenhouse impact due to the use of combustible fuels. Life cycle viewpoint and relative radiative forcing commitment. J Environ Manag 42(3):458-469. https://doi.org/10.1007/s00267-008-9145-z

Klöpffer W, Grahl B (2014) Life Cycle Assessment (LCA). A guide to best practice. Wiley-VCH Verlag GmbH \& Co. KGaA, Weinheim

Laratte B, Guillaume B, Kim J, Birregah B (2014) Modeling cumulative effects in life cycle assessment. The case of fertilizer in wheat production contributing to the global warming potential. Sci Total Environ 481:588-595. https://doi.org/10.1016/j.scitotenv.2014.02. 020

Lebailly F, Levasseur A, Samson R, Deschênes L (2014) Development of a dynamic LCA approach for the freshwater ecotoxicity impact of metals and application to a case study regarding zinc fertilization. Int J Life Cycle Assess 19(10):1745-1754. https://doi.org/10.1007/ s11367-014-0779-1

Levasseur A, Lesage P, Margni M, Brandão M, Samson R (2012) Assessing temporary carbon sequestration and storage projects through land use, land-use change and forestry. Comparison of dynamic life cycle assessment with ton-year approaches. Clim Chang 115(3/4):759-776. https://doi.org/10.1007/s10584-012-0473-x

Levasseur A, Lesage P, Margni M, Samson R (2013) Biogenic carbon and temporary storage addressed with dynamic life cycle assessment. J Ind Ecol 17(1):117-128. https://doi.org/10.1111/j.15309290.2012.00503.x

Levasseur A, Lesage P, Margni M, Samson R, Deschênes L (2010) Considering time in LCA. Dynamic LCA and its application to global warming impact assessments. Environ Sci Technol 44(8): 3169-3174

Levine SH, Gloria TP, Romanoff E (2007) A dynamic model for determining the temporal distribution of environmental burden. J Ind Ecol 11(4):39-49. https://doi.org/10.1162/jiec.2007.1244

Littell JH, Corcoran J, Pillai VK (2008) Systematic reviews and metaanalysis. Oxford University Press, Oxford

Lozano R (2008) Envisioning sustainability three-dimensionally. J Clean Prod 16(17):1838-1846. https://doi.org/10.1016/j.jclepro.2008.02. 008

Mallapragada D, Mignone BK (2017) A consistent conceptual framework for applying climate metrics in technology life cycle assessment. Environ Res Lett 12(7). https://doi.org/10.1088/1748-9326/ aa7397

McManus MC, Taylor CM (2015) The changing nature of life cycle assessment. Biomass Bioenergy 82:13-26

Menten F, Tchung-Ming S, Lorne D, Bouvart F (2015) Lessons from the use of a long-term energy model for consequential life cycle assessment. The BTL case. Renew Sust Energ Rev 43:942-960. https:// doi.org/10.1016/j.rser.2014.11.072

Moura Costa P, Wilson C (2000) An equivalence factor between CO2 avoided emissions and sequestration; description and applications in forestry. Mitig Adapt Strateg Glob Chang 5:51-60

O’Hare M, Plevin RJ, Martin JI, Jones AD, Kendall A, Hopson E (2009) Proper accounting for time increases crop-based biofuels' greenhouse gas deficit versus petroleum. Environ Res Lett 4(2):24001. https://doi.org/10.1088/1748-9326/4/2/024001

Omura M (2004) Cost-benefit analysis revisited. Is it a useful tool for sustainable development? Kobe Univ Econ Rev (50):43-58 
Owens JW (1997a) Life-cycle assessment. Constraints on moving from inventory to impact assessment. J Ind Ecol 1(1):37-49

Owens JW (1997b) Life-cycle assessment in relation to risk assessment. An evolving perspective. Risk Anal 17(3):359-365. https://doi.org/ 10.1111/j.1539-6924.1997.tb00874.x

Drucker PF (1954) The practice of management. Harper, New York

Peters GP, Aamaas B, Lund MT, Solli C, Fuglestvedt JS (2011) Alternative "global warming" metrics in life cycle assessment. A case study with existing transportation data. Environ Sci Technol 45(20):8633-8641. https://doi.org/10.1021/es200627s

Richards KR (1997) The time value of carbon in bottom-up studies. Crit Rev Environ Sci Technol 27(sup001):279-292. https://doi.org/10. 1080/10643389709388526

De Rosa M, Schmidt J, Brandão M, Pizzol M (2017) A flexible parametric model for a balanced account of forest carbon fluxes in LCA. Int J Life Cycle Assess 22(2):172-184. https://doi.org/10.1007/s11367$016-1148-\mathrm{z}$

de Bikuña S, Koldo, Hamelin L, Hauschild MZ, Pilegaard K, Ibrom A (2018) A comparison of land use change accounting methods. Seeking common grounds for key modeling choices in biofuel assessments. J Clean Prod 177:52-61. https://doi.org/10.1016/j. jclepro.2017.12.180

Schwietzke S, Griffin WM, Matthews HS (2011) Relevance of emissions timing in biofuel greenhouse gases and climate impacts. Environ Sci Technol 45(19):8197-8203. https://doi.org/10.1021/es2016236

Shimako AH, Tiruta-Barna L, Ahmadi A (2017) Operational integration of time dependent toxicity impact category in dynamic LCA. Sci Total Environ 599:806-819. https://doi.org/10.1016/j.scitotenv.2017.04.211

Shimako AH, Tiruta-Barna L, de Faria B, Barbara A, Ahmadi A, Spérandio M (2018) Sensitivity analysis of temporal parameters in a dynamic LCA framework. Sci Total Environ 624:1250-1262. https://doi.org/10.1016/j.scitotenv.2017.12.220

Soimakallio S, Cowie A, Brandao M, Finnveden G, Ekvall T, Erlandsson $\mathrm{M}$ et al (2015) Attributional life cycle assessment. Is a land-use baseline necessary? Int J Life Cycle Assess 20(10):1364-1375. https://doi.org/10.1007/s11367-015-0947-y

Su S, Li X, Zhu Y, Lin B (2017) Dynamic LCA framework for environmental impact assessment of buildings. Energy Build 149:310-320. https://doi.org/10.1016/j.enbuild.2017.05.042

Tiruta-Barna L, Pigné Y, Gutiérrez N, Tomás, Benetto E (2016) Framework and computational tool for the consideration of time dependency in life cycle inventory. Proof of concept. J Clean Prod 116:198-206. https://doi.org/10.1016/j.jclepro.2015.12.049

Tranfield D, Denyer D, Smart P (2003) Towards a methodology for developing evidence-informed management knowledge by means of systematic review. Br J Manag 14(3):207-222. https://doi.org/ $10.1111 / 1467-8551.00375$ de Haes U, Helias A, Jolliet O, Finnveden G, Hauschild M, Krewitt W, Müller-Wenk R (1999) Best available practice regarding impact categories and category indicators in life cycle impact assessment. Int $\mathrm{J}$ Life Cycle Assess 4(3):167-174. https://doi.org/10.1007/ BF02979453

van Zelm R, Huijbregts MAJ, van Jaarsveld HA, Reinds GJ, de Zwart D, Struijs J, van de Meent D (2007) Time horizon dependent characterization factors for acidification in life-cycle assessment based on Forest Plant species occurrence in Europe. Environ Sci Technol 41(3):922-927

Wang J, Zhang Y, Wang Y (2018) Environmental impacts of short building lifespans in China considering time value. J Clean Prod 203: 696-707. https://doi.org/10.1016/j.jclepro.2018.08.314

WCED World Commission on Environment and Development (1987) Our common future: report of the world commission on environment and development. Oxford University Press, Oxford

Weitzman ML (1998) Why the far-distant future should be discounted at its lowest possible rate. J Environ Econ Manag 36(3):201-208. https://doi.org/10.1006/jeem.1998.1052

Yu B, Sun Y, Tian X (2018) Capturing time effect of pavement carbon footprint estimation in the life cycle. J Clean Prod 171:877-883. https://doi.org/10.1016/j.jclepro.2017.09.266

Yuan, C. Y.; Simon, R.; Mady, N.; Dornfeld, D. (2009): Embedded temporal difference in life cycle assessment. Case study on VW golf A4 car. In IEEE (ed) 2009 IEEE International Symposium on Sustainable Systems and Technology. Phoenix, AZ, USA, 18-20 May 2009

Yuan C, Wang E, Zhai Q, Yang F (2015) Temporal discounting in life cycle assessment. A critical review and theoretical framework. Environ Impact Assess 51:23-31. https://doi.org/10.1016/j.eiar. 2015.01.001

Zimmermann BM, Dura H, Baumann MJ, Weil MR (2015) Prospective time-resolved LCA of fully electric supercap vehicles in Germany. Integr Environ Assess Manag 11(3):425-434. https://doi.org/10. 1002/ieam.1646

Zimmermann BM, Dura H, Weil M (2014) Towards time-resolved LCA of electric vehicles in Germany. Metall Res Technol 111(3):169 178. https://doi.org/10.1051/metal/2014009

Zumsteg JM, Cooper JS, Noon MS (2012) Systematic review checklist. A standardized technique for assessing and reporting reviews of life cycle assessment data. J Ind Ecol 16(Suppl 1):12-21. https://doi.org/ 10.1111/j.1530-9290.2012.00476.x

Publisher's note Springer Nature remains neutral with regard to jurisdictional claims in published maps and institutional affiliations. 